\title{
Hand Preference and Creativity of Papua University Student
}

\author{
Vionita Putri ${ }^{1}$, Elda Irma Jeanne Joice Kawulur ${ }^{1 *}$, Febriza Dwiranti ${ }^{1}$, Sabarita Sinuraya ${ }^{1}$, Sita \\ Ratnawati ${ }^{1}$
}

${ }^{1}$ Biology Departement Mathematic and Natural Science Faculty Papua University, Manokwari, Indonesia

DOI: $10.29303 /$ jppipa.v8i1.914

\section{Article Info}

Received: August 24, 2021

Revised: January 10, 2022

Accepted: January 16, 2022

Published: January 31, 2022

\begin{abstract}
Human has a preference to use their hands for various manual activities. Lefthanded preference is people who tend to use their left hand to perform various manual activities, while right-handed people tend to use right-handed. Any researches show that lefthanded preference for more creativity was influenced by the dominant use of the right brain and bigger corpus callosum. The research aims to determine the percentage of left-handed preference and their creativity in Universitas Papua, Manokwari Papua Barat. The method used in this research is the descriptive method. Data collection used a questionnaire to evaluate individual hand preference using Handedness Questionnaire and to determine individual creativity using Adjective Check List. The percentage of left-handed people in UNIPA were $9.3 \%$ or lower than right-handed and higher than ambidextrous. Our study supports the statement about selection in handedness in the traditional society which showed a higher percentage of left-hander as advantages related to using hand intensively. The percentage of left-handed males and females was almost equal and strongly left-handed was higher in females. The percentage of creative people was higher in left-handed, especially in males.
\end{abstract}

Keywords: Left-handed; Creativity; Papua University; Student

Citation: Putri, V., Kawulur, E. I. J. J., Dwiranti, F., Sinuraya, S., \& Ratnawati, S. (2022). Hand Preference and Creativity of Papua University Student. Jurnal Penelitian Pendidikan IPA, 8(1), 257-262. https://doi.org/10.29303/jppipa.v8i1.914

\section{Introduction}

Human has a preference to use one hand for various manual activities. Individual who tends to use the left hand to perform various manual activities is called left-handed, while kinan (right-handed) is an individual who tends to use their right-handed. The population of left-handed is only $10 \%$ in the world. A higher percentage of left-handed people was found in males (Llaurens, et al., 2009; Raymond et al., 1996). Over 200.000 years or from the 18th century to the 20th century the percentage of left-handed people has ranged around $8 \%$ to $10 \%$ (Sommer and Khan, 2009).

Creativity is currently a central issue not only in the world of education, but also in various aspects of daily life. An educator is required able to design the implementation of creative learning. Likewise, outcome-based education requires students and lecturers synergize together to produce innovative works that are beneficial to the community. Innovative product are produced by creative thinking. Several studies reveal that the cognitive ability of creativity is related to hand preference (Abbasi, et al., 2011; Kohen, et al., 1995).

Hand preference is influenced by genetic, development, and environmental factors. Left-handed parents tend to transmit left-handed traits to their offspring. The percentage of the left-handed offspring from right-handed parents was smaller than lefthanded offspring from left-handed parents and or parents with left-handed combinations (Mckeever, 2000). High levels of the testosterone hormone during fetal development will retard the development of leftbrain nerves so that movement of the body on the right which is controlled by the left brain becomes weak (Llaurens, et al., 2009). Left hand use in Asian people is 
considered mannerless while in western it is considered normal. A higher percentage of left-handed people was found in European-Americans than Asians. The research found about $0.7 \%$ of students in Taiwan use their left hand to write, while students in Berkeley California were about $9.9 \%$ use their left hand to write (Teng, et al., 1976). Those study showed that culture also influences hand preference.

Two methods can be used to measure hand preference, hand ability and hand preference questionnaire. Hand ability method related to measuring muscle strength and hand skills, while handing preference questionnaire related to evaluating which hand is likely to used for some activities. A method commonly used to measure hand preference is a hand preference questionnaire. Hand preference questionnaire is a self assessment that asks the subject to choose which hand their use to do manual activities as throw a ball, hammer, draw, etc (Strien, 2002).

Domination in using right and left handed is related to brain function. Right handed people showed domination in the left brain while left handed people showed domination in the right brain (Burke et al., 2009). The right brain has abilities in creativity, art, music, imagination, and socialize; while the left brain has abilities in logic, linguistic, rational thinking, and analysis (Sumardi, 2014). Left handed people were more creative because they are dominant using the right brain (Burke, et al., 2009). The corpus callosum which is a function related to creativity, was greater in left handed people than right handed people so they are more creative (Luders, et al., 2010).

The research of left handed creativity is still a matter of debate because there is a lack of evidence to ensure the statement. Research conducted by Abbasi, et al., (2011) found that left handed students were more creative than right handed students, same with research conducted by Coren (1995) especially in males students. Those study contrary to research conducted by Nurhayu (2015) which found higher creativity in right handed students.

Habits in patterns of thinking and doing daily activities on students, lecturers, and employees in Papua University that underlying researcher to study about hand preference and their creativity in Papua University, Manokwari. Therefore, our study aims to determine percentage of handedness and whether left handed people more creative than right handed in Papua University.

\section{Method}

This research was carried out in October 2020 May 2021. The population in this research were academic civitas of Papua University. The samples obtained were 410 people consisting of 380 students, 26 lecturers, and 4 employees.

Descriptive method was applied in this research. The preparation includes creating informed consent, questionnaire, and do the questionnaire validation. Prior to data collection, we explain the outline of the research, guarantee to writing anonymous in data processing, no disseminate data outside the research interests, no risk when data collection, and freedom in resign from research. They signed the informed consent if they agree as respondent. Data collection was done by distributing an online questionnaire and hardcopy questionnaire according to covid-19 health protocol. The online questionnaire was done by distributing a google form link via social media. Hardcopy questionnaire was distributed directly to the field. Hand preference questionnaire referring to Strien (2002). The creativity assessment questionnaire is Adjective Check List (ACL) referring to Gough (1979).

The data was given a scoring to categorize hand preference and creativity, then analyzed statistically descriptive. The hand preference questionnaire consists of 10 manual activities. Respondents were asked to checklist what hand they prefer to perform every manual activity. In scoring hand preference, -1 point is given each time the left hand is checked, 0 points is given each time either ambidextrous hand is checked and +1 point is given each time the right hand is checked. The total score between -10 and 4 was categorized as left handed, while a total score between 3 and 3 was categorized as ambidextrous and a total score between 4 and 10 was categorized as right handed. Left-handed is categorized as weakly lefthanded and strongly left-handed. The total score between -10 and -8 are categorized as strongly lefthanded and the total score between -7 and -4 categorized as weakly left-handed (Strien et al, 2005). The creativity assessment questionnaire is an Adjective Check List which contains 30 adjective items consisting of 18 positive items indicating creative individuals and 12 negative items indicating non-creative individuals. In scoring Adjective Check List, 1 point is given each time one of 18 positive items is checked, and -1 point is given each time one of 12 negative items is checked. The range of total scores is therefore -12 to +18 . Total score $\leq 3$ categorized as not creative, while total score $>$ 3 are categorized as creative (Gough, 1979)

\section{Result and Discussion}

Total respondents involved in this study were 410 people consisting of 251 females and 159 males, aged range 17-60 years old with average aged of 22.6 years old. Based on Table 1, the percentage of left-handed people in UNIPA were $9.30 \%$, ambidextrous were $4.1 \%$ and right-handed were $86.60 \%$. The percentage of left- 
handed people both males and females were $9.20 \%$ and $9.40 \%$. Those percentage was almost equal.

Table 1. The percentage of hand preference based on gender in UNIPA

\begin{tabular}{lllllll}
\hline \multirow{2}{*}{ Hand preference } & \multicolumn{2}{l}{ Gender (Sex) } & \multicolumn{3}{c}{ Total } \\
\cline { 2 - 6 } & \multicolumn{2}{l}{ Female } & Male & & \\
\cline { 2 - 6 } & $\mathrm{n}$ & $\%$ & $\mathrm{n}$ & $\%$ & $\mathrm{~N}$ & $\%$ \\
\hline Left-handed & 23 & 9.20 & 15 & 9.40 & 38 & 9.30 \\
Ambidextrous & 8 & 3.20 & 9 & 5.60 & 17 & 4.10 \\
Right-handed & 220 & 87.60 & 135 & 850 & 355 & 86.60 \\
Total & 251 & 100 & 159 & 100 & 410 & 100 \\
\hline
\end{tabular}

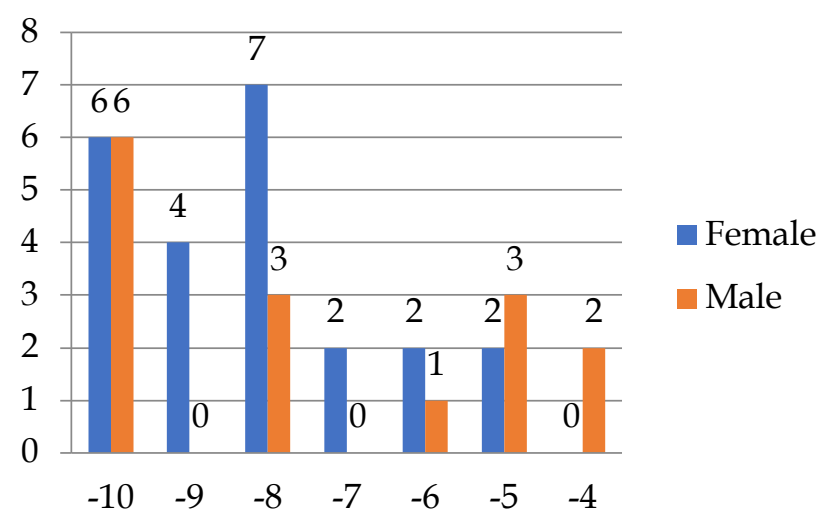

Figure 1. The number of left-handed Respondents Both Males and Females Based on the Total Score
Based on Figure 1, people with total score between -10 and -8 are categorized as strongly left-handed and total score between -7 and -4 are categorized as weakly left-handed. The number of strongly left-handed females were 17 people and strongly left-handed males were 9 people, while the number of weakly left-handed both males and females was equal. Females are categorized as left-handed if they do 5 or more activities, while males are categorized as left-handed if they do 4 or more activities.

Based on Table 2, the percentage of creative lefthanded females were $8.7 \%$ while creative left-handed males were $33.30 \%$. The percentage of creative ambidextrous females were $12.50 \%$, while creative ambidextrous males were $22.20 \%$. The percentage of creative right-handed female were $14.1 \%$ while creative right-handed male was $20 \%$. These results showed that percentage of creative males with left-handed preference was higher than females. On contrary, the percentage of non creative in both sex are same relatively in right and ambidextrous hand.

Table 1. The percentage of people with creativity based on hand preference and gender in UNIPA

\begin{tabular}{|c|c|c|c|c|c|c|c|c|}
\hline \multirow{3}{*}{$\begin{array}{l}\text { Hand } \\
\text { Preference }\end{array}$} & \multicolumn{4}{|c|}{ Female } & \multicolumn{4}{|c|}{ Male } \\
\hline & \multicolumn{2}{|c|}{ Creative } & \multicolumn{2}{|c|}{ No Creative } & \multicolumn{2}{|c|}{ Creative } & \multicolumn{2}{|c|}{ No Creative } \\
\hline & $\mathrm{n}$ & $\%$ & $\mathrm{~N}$ & $\%$ & $\mathrm{~N}$ & $\%$ & $\mathrm{n}$ & $\%$ \\
\hline Left & 2 & 8.70 & 21 & 91.30 & 5 & 33.30 & 10 & 66.70 \\
\hline Ambidextrous & 1 & 12.50 & 7 & 87.50 & 2 & 22.20 & 7 & 77.80 \\
\hline Right & 31 & 14.10 & 189 & 85.90 & 27 & 20 & 108 & 80 \\
\hline
\end{tabular}

The left-handed factors found in respondent were genetic, environment and habit. Based on Figure 4.50, the highest left-handed factor was genetic $(60.50 \%)$ while the lowest factor was environment $(10.50 \%)$.

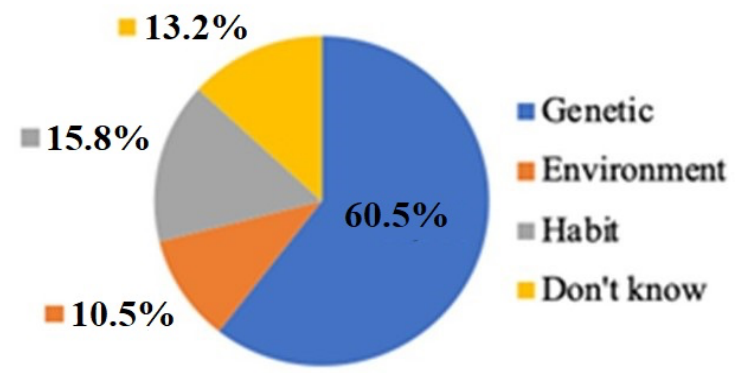

Figure 2. The left-handed Factors of Respondents at UNIPA

The hand preference in UNIPA showed that the percentage of left-handed people $(9.30 \%)$ was in line with research conducted by Sommer and Kahn (2009). Those study found that left-handed people have a lower percentage than right handed people and the range only between $8 \%$ and $10 \%$ in a population, while ambidextrous people are rarely found. Study of Strien (2002) categorized ambidextrous people as a left handed. Thus, if we using those categorize so the percentage of left handed people in Manokwari will increase to be $13.40 \%$. The previous study states left handed people never occur at frequency close to $10 \%$ or $25 \%$ in the world (Sommer and Khan, 2009; Groothius, et al., 2013). It indicates that natural selection force are mantaining the existence of this phenotipe.

The percentage of left-handed people in Bogor $(7.30 \%)$ according to Nurhayu (2015) was lower than in Manokwari. This difference is probably related to the different geographical areas between Bogor as a modern society, while Manokwari associated with traditional society. Nurhayu, et al., (2019) states in modern society there was a decreased in the percentage of left-handed compared to traditional society. In traditional society, like Manokwari, where violent 
conflict and demonstration of the people or students, which destroyed buildings and roads, cut trees as roadblock using hand or traditional tool relatively frequent. Also, the use of a traditional tool for doing all activities like household and farming rely on the manual hand, while in modern society extensively use automation tool in manual labour. Thus, modern people rely less on used hand for doing activities. Therefore, traditional dan modern society differs in the selection of handedness.

The minority of left handed and handedness differences between modern and traditional society are related to the fighting hypothesis. It postulates that left hander would have a greater chance of winning than right hander in a fight and interactive/combat sports with physical contact. The strategic aspect and innate superiority both explain a higher winning chance of left hander (Groothius, et al., 2013).

The percentage of left-handed preference in UNIPA for both males and females was equal. Our study is different from the research conducted by Nurhayu (2015) on students in Bogor. They found that the percentage of left-handed males $(9.30 \%)$ was higher than left-handed females (5.60\%). Based on Geschwind and Galaburda's theory of lateralization of brain function, left-handedness was more common in males due to the higher production of testosterone in the fetus during the prenatal phase. High levels of testosterone can involve the right brain to develop more than the left brain as a result, the right side of the body's motor which is controlled by the left brain will be weaker than the left side of the body (Llaurens, et al., 2009)

Most of the left-handed people found in UNIPA were categorized as strong-handed, with females showed the stronger left-handed activity than males. Our study was similar with research by Nurhayu (2015) which found that left-handed activity was stronger in female because female was categorized as left-handed if they did 5 or more activities while the male was categorized as left-handed if they did 2 or more activities. In this study, the total score between -10 and -4 was categorized as left-handed, while research conducted by Nurhayu (2015) was categorized as lefthanded if the total score was between -10 and -1 . There are differences in the scoring method used in this study with research conducted by Nurhayu (2015) so that the categorization of hand use preference is different.

The more creative of left handed people in Papua University similar to research conducted by Abbasi, et al., (2011) to students in Iran. Also, males left hander more creative than females in line with research by Coren (1995). According to Razumnikova (2004) creativity is higher in males as evidenced by greater information processing in the right hemisphere related to the elements of creativity. Therefore, there are a different hemisphere organization in males and females during creative thinking.

According to neurological research, left-handed people are more dominant in using the right brain, where the right brain is related to creativity because the right brain is more active in problem-solving and creating new ideas than the left brain (Atherton, et al, 2003). Another study found that left-handed people have a larger corpus callosum. Corpus callosum is a group of nerve fibers that connect the left brain and right brain. It function as transfer information from one hemisphere to another, thereby unifying brain activity and giving the brain the ability to perform complex functions (Gazzaniga, 2000). Thus the greater of connectivity between the left and right brain can improve cognitive creative abilities (Luders, et al., 2010).

The environment is also one of the factors that affect creativity in left-handed people. According to Burke, et al., (2009), life in a world dominated by righthanded requires left-handed to be more flexible and creative in dealing with their environment. On another side, the presence of left-handed people in the world of work which is dominated by right-handed people will have a positive impact because each of those people has unique characteristics thinking.

A series of cognitive processes in generating innovative ideas which is novel and useful involves the interaction between divergent and convergent thinking (Prochazkova \& \& Hommel, 2020). Those two ways of human thinking become the center of creative cognitive (Zhang, et al. 2020). Convergent thinking is focuses on one correct answer. They usually have the ability to analyze a problem well by using relevant information and based on facts and data. Convergent people narrow their analytical thinking, serial and persistent to converge on single solution/answer to solve the problem. Divergent thinking is more flexible, associative, and paralel in providing solutions. They solve a ploblem with several alternative answers/solution. People with divergent thinking usually generate new ideas through gathering as much information as possible which is sometimes irrelevant and different from the usual. The ideas that arise are sometimes based on intuition. Interaction between divergent and convergent thinking will impact to quality of product in generating cognitive creative (Prochazkova \& Hommel, 2020; Zhang, et al., 2020).

The highest factor causes of left-handed in UNIPA was genetic. Hand preference is an inherited trait from parents to their offspring. Research conducted by McKeever (2000) to 1572 families found the percentage of left-handed offspring from right-handed parents was $16.67 \%$, left-handed offspring from left-handed parents was $40.63 \%$, while left-handed offspring from lefthanded mothers and right handed fathers was $23.27 \%$ 
and left-handed offspring from right-handed mothers with left-handed fathers was $18.13 \%$. This percentage indicates that left-handed offspring from left-handed parents and parents with any other handedness combination was higher than left-handed offspring from non-handed parents. So it can be concluded that left-handed offspring tend to have left-handed parents. Llaurens, et al., (2009) states that left-handed parents have left-handed offspring with a percentage $30-40 \%$. The percentage of left-handed children from lefthanded mothers and right handed fathers was higher than left-handed fathers and right-handed mothers, this indicates that there is a strong maternal effect on the offspring. Maternal effects only occur in boys, not girls and on the other hand, paternal effects are passed on to girls.

\section{Conclusion}

The percentage of left-handed people in UNIPA was lower than right-handed people and higher than ambidextrous people. The percentage of left-handed people both males and females were almost equal. The creativity was found to be higher in left-handed people than in ambidextrous and right-handed people, especially in males. The increase of using handedness intensively migh be the reason left handed traits were still mantained in Manokwari people.

\section{Acknowledgements}

Many thanks to Parita Wahyudi for all assistance in this research and Civitas Academica Papua University for their participant and support.

\section{References}

Abbasi, M., Shahbazzadegan, B., \& Samadzadeh, M. (2011). Survey of Relationship between Creativity and Lateral Dominance in Guidance School Students. Social and Behavioral Sciences, 28, 293 299.

http://dx.doi.org/10.1016/j.sbspro.2011.11.056

Artheton, M., Zhuang, J., Bart, W.M., Hu, X., He, S. (2003). A functional MRI study of high-level cognition I. The game of chess Cognitive Brain Research, 16. 26-31. https://doi.org/10.1016/s09266410(02)00207-0

Beaton, A. A. (1997). The relation of planum temporale asymmetry and morphology of the corpus callosum to handedness, gender, and dyslexia: a review of the evidence. Brain and language, 60(2), 255-322. https://doi.org/10.1006/brln.1997.1825

Burke, B.F., Chrisler, J.C., \& Devlin, A.S. (2009). The Creative Thinking, Environmental Frustration, and Self Concept of Leftand Right-handers. Creativity
Research Journal, 2(4),

279-285.

https://doi.org/10.1080/10400418909534324

Coren,S. (1995). Differences in Divergent Thinking as a Function of Handedness and Sex. The American Journal of Psychology, 108(3), 311-325. Retrieved from: https:// pubmed.ncbi.nlm.nih.gov/7573608/

Gazzaniga, M.S. (2000). Cerebral specialization and interhemispheric communication: Does the corpus callosum enable the human condition. Journal of Psychology. 123(7).

1293-1326. https://doi.org/10.1093/brain/123.7.1293

Gough, G. A. (1979). A Creative Personality Scale for the Adjective Check List. Journal of Personality and Social Psychology, 37(9), 1398-1405. https://psycnet.apa.org/doi/10.1037/0022$\underline{3514.37 .8 .1398}$

Llaurens,V., Raymond, \& M.,Faurie, C. (2009). Why Are Some People Left-Handed? An evolutionary perspective. Phil. Trans.R.SocB, 364, 881-894. https://doi.org/10.1098/rstb.2008.0235

Luders, E., Cheirbuin, N., Thompson, P.M., Gutman, B., Arstey, K.J., Sachdev,P., Toga, A.W. (2010). When more is less: Associations between Corpus Callosum size and handedness lateralization. NeuroImage, 52, 43-49. https:// doi.org/10.1016/j.neuroimage.2010.04.016

Masud, Y., Ajmal, M.A. (2012). Left-handed People in a Right-handed World: A Phenomenological Study. Pakistan Journal of Social and Clinical Psychology, 10(1), 49-60. Retrieved from: https://psycnet.apa.org/record/2012-17550-008

McKeever, W.F. (2000). A new family handedness sample with finding consistent with X-linked transmission. British Journal of Psychology, 91, 21-39. https://doi.org/10.1348/000712600161655

Nurhayu, W. (2015). Frequency of People with LeftHanded Preference and Their Creativity in Bogor, West Java. Skripsi. Institut Pertanian Bogor, Bogor.

Nurhayu, W., Nila, S., Widayati, K.A., Rianti, P., Suryobroto, B., Raymond, M. (2019). Handedness Heritability in industrialized andnonindustrialized societies. Heredity: Springer Nature, 124, 313-324. https://doi.org/10.1038/s41437-019-0274-3

Prochazkova, L. Hommel, B. (2020). Altered States of consciousness and creativity. Netherlands: Elsevier Inc

Raymond, M., Pontier, D., Dufour, A.B., Moller, A.P. (1996). Frequency-dependent Maintance of Lefthandedness in Humans. Proc.R.Soc.Lond.B, 263, 1627-1633.

https://doi.org/10.1098/rspb.1996.0238

Razumnikova, O.M. (2004). Gender differences in hemispheric during divergent thinking an EEG investigation in human subjets. Neuroscience, 362, 193-195.

https://doi.org/10.1016/j.neulet.2004.02.066 
Sommer, I.E.C., Khan, R.S. (2009). Language Lateralization and Psychosis. New York: Cambridge University Press.

Strien, J.W.V. (2002). The Dutch Handedness Questionnare. Paper. Department of Psychology. Erasmus University. Rotterdam.

Strien. J.W.V., Haselen, G.C.L.V., Hagen, J.M.V., Coo, I.F.M., Frens, M.A., Geert, J.N.V.D. (2005). Increase Prevalences of Left-handedness and Left-eye Sighting Dominance in Individuals with WilliamsBeuren Syndrome. Jounal of Clinical amd Experimental Neuropsychology, 27(8), 967-976. https://doi.org/10.1080/13803390490919119

Sumardi. (2014). Perbandingan Kinerja Otak Kiri dan Otak Kanan dalam Perkuliahan Mahasiswa Jurusan Pendidikan Fisika Fakultas Tarbiyah dan Keguruan UIN Alauddin Makassar. Skripsi. Universitas Islam Negeri Alauddin Makassar, Makassar

Teng, E.L., Lee, P.H., \& Chang, P.C. (1976). Handedness in a Chinese Population: Biological, Social, and Pathological Factors. Science, 193, 1148-1150.

Willems, R. M., Francks, C. (2014). Your Left-Handed Brain. Neuroscience, 3, 1-4. https://doi.org/10.1126/science.986686

Zhang, W, Sjoerds Z, Hommel, B. (2020). Metacontrol of human creativity: The neurocognitive mechanisms of convergent and divergent thinking. NeuroImage, 210, https://doi.org/10.1016/j.neuroimage.2020.11657 2 